\title{
The Impact of the COVID-19 Pandemic on University and College Students in New Jersey
}

\section{Julie Kalabalik-Hoganson*}

Department of Pharmacy Practice, Fairleigh Dickinson University, School of

Pharmacy and Health Sciences, USA

*Corresponding Author: Julie Kalabalik-Hoganson, Department of Pharmacy Practice, Fairleigh Dickinson University, School of Pharmacy and Health Sciences, USA.
Received: May 06, 2021

Published: June 12, 2021

(C) All rights are reserved by Julie

Kalabalik-Hoganson.

\begin{abstract}
As of May 2021, the COVID-19 pandemic has resulted in over 32 million cases and 574,679 deaths in the United States. In New Jersey alone, the number of cases have exceeded 1 million and deaths over 25,000 [1]. The pandemic has disrupted education systems for students of all ages across the globe. This mini review provides a summary of the published literature on the impact of COVID on university and college students in New Jersey. The search strategy included the MEDLINE database and MESH search terms were "covid-19 or coronavirus or 2019-ncov or sars-cov-2 or cov-19" and "university students or college students" and "New Jersey". The following limiters were applied: English language and publication date January 1, 2020, to current date. The nine search results were focused on the themes of (1) mental health, (2) university accessibility services, communications, and internet connectivity, (3) ageism and (4) alcohol consumption and sexual violence.
\end{abstract}

Keywords: COVID-19; Drinks; New Jersey

Impact on mental health

Three studies reported on the mental health consequences of the COVID pandemic on university or college students in New Jersey. Kecojevic and colleagues from the Department of Public Health at William Paterson University in New Jersey conducted a cross-sectional survey of 162 college students in an introductory core curriculum course to assess factors associated with the increased levels of mental health burden. The median age of the sample was 19 years (range 18 to 37), the majority female (71\%) and non-White (63\%). Two-thirds were freshman and one-third health majors. Most students had a fundamental knowledge of COVID transmission and symptoms and trusted official sources such as government sources and medical professionals. Many students reported academic difficulties; $73.5 \%$ reported problems with focus- ing on academic work and problems with online learning. Students also reported issues with obtaining hygiene supplies, medications, and losing work. About $22 \%$ of students reported difficulty getting food. Higher levels of anxiety were reported in students who were not freshmen and who spent more than 1 hour per day reading about COVID. Students with greater inability to focus on academic work and who had a greater concern over COVID had greater risk of somatization. Females, those unable to focus on schoolwork, and those with trouble finding medications and cleaning supplies were more likely to report higher levels of stress [2]. Kibbey and colleagues from Rutgers evaluated the psychological stress associated with COVID in a sample of 641 undergraduates. Almost half of the students reported increased psychological distress. Students reported health anxiety, general anxiety, and depression. Female stu- 
dents were more associated with increased psychological distress. Those who had an immediate acquaintance who had COVID were more likely to report increased psychological distress. Those who experienced recent viral symptoms or had underlying medical conditions were more likely to experience psychological distress [3]. Kleiman and colleagues from Rutgers assessed the mental health impact of COVID on undergraduate students through smartphonebased ecological momentary assessments of anxiety and optimism. COVID-related anxiety was higher than non-COVID specific anxiety. More than $75 \%$ of surveys demonstrated at least some level of COVID-related anxiety. There was a downward trend in anxiety in mid-June. Anxiety was higher on days with more new cases and deaths. Higher COVID-related anxiety was associated with feelings of sadness, general anxiety, and desire to drink alcohol and use drugs. Optimism was more likely in those who felt supported by others and their university [4].

University accessibility services, communications, and internet connectivity

Three studies evaluated university accessibility services and communications and student internet connectivity. Meleo-Erwin and colleagues aimed to describe the availability of remote instruction and counseling services on disability websites for colleges in the New York City metropolitan area. Investigators evaluated disability and accessibility pages of websites for remote instructional resources, a way to make appointments with counseling centers, and links to counseling centers. Nearly one-fifth of colleges and universities had no link to disability or accessibility services on their websites. Availability of instructional resources and ways to make an appointment with counseling centers was scarcely available on the disability pages of the 127 institutions. Many had remote instruction assistance available. There was no statistically significant association of school size with the availability of resources [5]. Mohlman and colleagues out of William Paterson University studied university-based communications for language during crisis communication and epidemic management. The authors used the Linguistic Inquiry and Word Count to evaluate written messages from universities to students about transitioning to online classes. More positive emotion and power words were used in communications to larger student bodies and the more likely COVID updates were posted on university websites within 3 months. The authors recommended universities create communications guided by crisis management models [6]. Katz and colleagues out of Rutgers conducted an anonymous, online survey of 2,913 undergraduate college students from 30 universities. This study examined the relationship between constrained access to the internet and internet-connecting devices and remote learning experiences. Students with internet connectivity challenges and difficulty with communicating with instructors had lower remote learning proficiency. Student with more financial difficulties had more issues with connectivity and communication with faculty during remote learning and lower remote learning proficiency. Factors associated with remote learning proficiency were consistent internet connectivity and the ability to communicate with professors [7].

\section{Benevolent ageism}

Apriceno and colleagues examined the views of college students on older adults with regards to healthcare and employment. These investigators distributed an online survey in which they evaluated how college students viewed giving priority to older adults in three health care-related scenarios and three employment scenarios. Benevolent ageism, in which older adults are viewed in a positive light, predicted higher priority for older adults to receive health care with regards to COVID-19 vaccine, COVID-19 testing, and triage and to retain their job and work from home. Those with hostile ageism had lower priority ratings. This study linked benevolent or hostile ageism views amongst college students with priority rating for healthcare and employment for older adults [8].

\section{Alcohol consumption and sexual violence}

One study evaluated the impact of the pandemic on the drinking behavior of students. White and colleagues from Rutgers University developed an online survey which was completed by 312 college students and evaluated drinking behavior before and after university closures due to the COVID pandemic. The number of drinks per week and maximum drinks per day decreased when comparing pre- to post-closure, but an increase in drinking days per week was observed. College students who moved from living with peers to living with parents had significantly greater decreases in drinking days, number of drinks per week, and maximum drinks in one day. Those who remained living with peers had significantly increased drinking frequency. The authors concluded that returning to live with parents may have been protective against heavy drinking [9]. Bennett and colleagues reported on supporting survivors of campus dating and sexual violence during COVID-19 from a social worker's perspective. The authors discussed the innovative meth- 
ods social workers who work in universities can use to address the mental health needs of dating and sexual violence student victims and to prevent violence during COVID. Recommendations include telehealth crisis response and counseling, virtual alternatives to workshops and trainings for education and prevention, prevention of technology-facilitated sexual violence, and incorporating antiracist themes into educational workshops [10].

\section{Conclusion}

This review reveals that the COVID pandemic has resulted in the majority of university and college students in New Jersey reporting higher anxiety and psychological distress. Many institutions in the New York City metropolitan areas lacked online disability pages that assist students with making an appointment with counseling centers. Students with internet connectivity issues suffered from lower remote learning proficiency. Benevolent ageism views amongst college students was associated with priority rating for healthcare and employment for older adults. The number of drinking days per week increased post-closure according to one study, and students returning to living with their parents may serve as a protection against heavy drinking. The pandemic has uncovered several areas for improvement within higher education institutions including addressing student mental health concerns, improving accessibility services, improving student internet connectivity, and the need to address student alcohol consumption and sexual violence on campus.

\section{Bibliography}

1. CDC. "COVID Data Tracker" (2021).

2. Kecojevic A., et al. "The impact of the COVID-19 epidemic on mental health of undergraduate students in New Jersey, crosssectional study". PloS One 15.9 (2020): e0239696. https://doi. org/10.1371/journal.pone.0239696

3. Kibbey MM., et al. "Anxiety, depression, and health anxiety in undergraduate students living in initial US outbreak "hotspot" during COVID-19 pandemic". Cognitive Behaviour Therapy (2021): 1-13. https://www.tandfonline.com/doi/full/10.108 $0 / 16506073.2020 .1853805$

4. Kleiman E M., et al. "Real-time Mental Health Impact of the COVID-19 Pandemic on College Students: Ecological Momentary Assessment Study". JMIR Mental Health 7.12 (2020): e24815. https://mental.jmir.org/2020/12/e24815/
5. Meleo-Erwin Z., et al. "Online support information for students with disabilities in colleges and universities during the COVID-19 pandemic". Disability and Health Journal 14.1 (2020): 101013. https://www.sciencedirect.com/science/article/pii/S193665742030145X

6. Mohlman J and Basch C. "The language of university communications during the COVID-19 pandemic". Journal of American College Health (2021): 1-4. https://www.tandfonline.com/ doi/pdf/10.1080/07448481.2020.1856116

7. Katz V S., et al. "Digital inequality, faculty communication, and remote learning experiences during the COVID-19 pandemic: A survey of U.S. undergraduates". PloS One 16.2 (2021): e0246641. https://doi.org/10.1371/journal.pone.0246641

8. Apriceno M., et al. "Prioritizing Health Care and Employment Resources During COVID-19: Roles of Benevolent and Hostile Ageism". The Gerontologist 61.1 (2021): 98-102. https://doi. org/10.1093/geront/gnaa165

9. White H R., et al. "Changes in Alcohol Consumption Among College Students Due to COVID-19: Effects of Campus Closure and Residential Change". Journal of Studies on Alcohol and Drugs 81.6 (2020): 725-730. https://www.jsad.com/doi/ abs/10.15288/jsad.2020.81.725

10. Bennett E R., et al. "Supporting survivors of campus dating and sexual violence during COVID-19: A social work perspective". Social Work in Health Care 60.1 (2021): 106-116. https://doi. org/10.1080/00981389.2021.1885566

\section{Volume 5 Issue 7 July 2021}

\section{(C) All rights are reserved by Julie Kalabalik-Hoganson.}

